PERSPECTIVAS DO GÊNERO DOCUMENTÁRIO PELA APROPRIAÇÃO DE ELEMENTOS DE LINGUAGEM DA TV DIGITAL INTERATIVA

\title{
Marcelo Sacrini
}

\section{Resumo}

O artigo apresenta uma reflexão sobre a TV Digital Interativa como novo espaço de apropriação dos elementos de linguagem pelo gênero documentário, além de elaborar algumas projeções quanto às possibilidades de aplicação do produto nesse meio. $\mathrm{O}$ Documentário Interativo Digital difere tanto do convencional, fílmico, quanto daquele produzido para a $W e b$, mesmo que reproduza e agregue alguns elementos de linguagem experimentados em ambos. A nova modalidade herdará do cinema a leitura linear embora possibilite, também, interrupções para o acesso a informações outras, multimídias, com características de uma linguagem hipertextual e interativa, agregando as possibilidades da não-linearidade e muti-linearidade. Além disso, os dados de retorno poderão ser direcionados ao provedor do conteúdo, conferindo ao documentário uma possibilidade didático-pedagógica como nunca antes experimentada pelo gênero.

\section{Palavras-chave}

Documentário; TV Digital Interativa; Apropriação de elementos de linguagem

\section{PERPECTIVES OF THE DOCUMENTARY GENDER FOR APPROPRIATION OF THE LANGUAGES ELEMENTS OF THE INTERACTIVE DIGITAL TV}

\begin{abstract}
The article presents a reflection of the Interactive Digital TV as a new feature of the appropriation of the languages elements by the documentary's kind. It also elaborates same projections of the possibilities of the application in that way. The Interactive Digital Documentary differs from both, conventional and web, even though reproduces same elements of languages used in both of them. The new kind will get the linear reading from he cinema, even though, it possibilities access to other sources of information, which have a interactive and hypertextually language.
\end{abstract}

\section{Key-words}

Documentary; Interactive Digital TV; Appropriation of the languages elements 


\section{ARTIGO \\ Comunicação \& Tecnologia}

\section{O CONCEITO DE DOCUMENTÁRIO}

O documentarismo consagrou-se mais pela prática de sua produção e experimentação que pela atribuição formal de seu conceito, principalmente porque impõe poucos critérios limitantes quanto à exploração de sua linguagem e formas de expressão. Mesmo assim, estudiosos abordam conceitualmente o documentário desde sua origem, com o surgimento do cinema.

O precursor do termo documentário foi o escocês John GRIERSON (1979), pioneiro no estudo do documentarismo e criador da Escola Britânica de Documentários, conhecida como a primeira no mundo a se dedicar ao estudo do assunto. Grierson foi responsável pelo reconhecimento da produção fílmica enquanto produção autoral específica, conforme entendemos atualmente, na Inglaterra dos anos de 1930.

Barsam (1974, p.1) definiu como gênero documentário aquele cujos "filmes registram, em película, fatos que ocorrem naturalmente em frente à câmera ou que são reconstruídos com sinceridade e por necessidades devidamente justificadas” enquanto, para Willian Guym, "se trata de uma ficção que tenta esconder a sua ficcionalidade" (GUYM Apud EITZEN, 1995, p.82).

Manuela Penáfria é uma autora contemporânea que reforça os aspectos sobre o registro da realidade ao afirmar que "o filme documentário é aquele que, pelo registro do que é e acontece, constitui uma fonte de informação para o historiador e para todos os que pretendem saber como foi e como aconteceu”. (PENAFRIA, 1999, p.20).

O conceito de documentário aqui empregado diz respeito às definições consagradas e aceitas pelos autores, produtores e estudiosos do assunto, desde a origem do gênero no fim do século XIX. O documentário surgiu com o advento do cinema (em 1895), e pode-se também entender que o cinema surgiu com o filme documentário, já que as primeiras filmagens registravam cenas do dia-a-dia da sociedade e indivíduos.

Será entendido como documentário, portanto, toda forma de registro e mediação da realidade humana nos diferentes suportes e meios considerando a incorporação das diversas 


\section{ARTIGO \\ Comunicação \& Tecnologia}

formas de linguagem e suas particularidades intrínsecas, em especial a $W e b^{1}$ e TV Digital Interativa.

É considerado ‘documentário convencional' aquele configurado para a veiculação no cinema, por se tratar da modalidade mais comum e consagrada na história do gênero documental. Não será feito o resgate histórico do documentarismo desde sua origem, por não se tratar do objetivo da pesquisa. Será abordada, entretanto, a modalidade conhecida como web-documentário pelas características que o compõem, por ser uma versão que utiliza as formas hipertextuais e hipemídia de linguagem, mais relevantes em relação a este estudo, e pela pressuposta compatibilidade com o suporte da TV Digital Interativa.

\section{DA PELÍCULA AO WEB-DOCUMENTÁRIO: A TECNOLOGIA COMO CONDICIONANTE DA LINGUAGEM DOCUMENTAL}

O modelo de produção do documentário e a linguagem adotada no decorrer de sua evolução sempre estiveram ligados aos desenvolvimentos técnicos e tecnológicos observados desde os primeiros experimentos cinematográficos até a atualidade, com o uso dos sistemas digitais de captação, edição e veiculação dos conteúdos. Sempre que um novo aparato ou possibilidade tecnológica foram inaugurados, novas formas de uso e apropriação de linguagens puderam ser também observadas. “A transição para uma nova fase do documentarismo [foi sempre] marcada pelo seu apelo à exploração das potencialidades dos novos equipamentos” (WINSTON, 1995, p.145).

O documentário nasceu com o cinema e teve, com o advento da televisão, uma grande retomada em relação à sua popularidade, principalmente com a chegada das emissoras de TV a cabo em meados do século XX. Atualmente, é possível assistir a filmes desse gênero transmitidos com possibilidades técnicas bastante avançadas, por meio do computador conectado à rede mundial de computadores.

\footnotetext{
${ }^{1}$ World Web Wide (WWW) é a interface gráfica da Rede Mundial de Computadores (Internet).
} 


\section{ARTIGO \\ Comunicação \& Tecnologia}

Esse novo meio requer a utilização de um suporte digital, em contrapartida ao anterior analógico, e garante uma qualidade muito maior no desenvolvimento dos produtos do gênero, na sua cópia e armazenamento.

A conservação e transmissão de imagens, sons e textos é, hoje, de uma confiabilidade sem precedentes. De igual modo, as tecnologias digitais são consideradas o melhor suporte para, com confiabilidade e durabilidade, se armazenar uma grande quantidade e diversidade de informação. (PENÁFRIA, 1999, p.90).

A tecnologia digital, além disso, permite a convergência de mídias numa escala jamais pensada nos suportes analógicos de produção documentarista. O documentário concebido para a Web (web-documentário) tende a ser um produto totalmente diferenciado do documentário convencional, já que são necessárias tecnologias multimídia tanto para a sua produção como veiculação.

O uso combinado desses recursos, assim como a interação possível entre produto e receptor, impõe ao web-documentário uma apropriação dos elementos de linguagem específicos da Web, meio onde é veiculado. Sendo assim, deve-se esclarecer que um filme documentário digitalizado, transmitido pela $W e b$, não se configura necessariamente como um web-documentário, pois não incorpora em si os elementos significativos de linguagem e os aspectos formais consagrados no meio.

Gregolin et al. (2002) apresentam os produtos abaixo considerando-os em seus estudos sobre tais apropriações e a capacidade educativa do web-documentário:

1. Becoming Human - http://www.becominghuman.org

2. Classic Motown - http://www.motown.com

3. 360 Degrees - http://www.360degrees.org

4. Elvis Number Ones - http://www.elvisnumberones.com.br

A modalidade, embora sua produção ainda tenha um caráter experimental, além de ser pouco difundida, explora com considerável eficácia os recursos multimídias suportados no ambiente $W e b$. O documentarismo fílmico, por sua vez, utiliza os recursos de linguagem consagrados no cinema, meio cuja origem se confunde com a origem do próprio documentarismo. 


\section{ARTIGO \\ Comunicação \& Tecnologia}

Pela afinidade com os recursos que privilegiam a imagem em movimento, o documentarismo poderá ser mais uma vez revigorado como a tv digital, meio que irá somar as funcionalidades da linguagem fílmica com aquelas experimentadas no meio computacional.

Imagina-se que na tv digital o novo produto preserve os elementos intrínsecos do documentarismo consagrado, aproveite elementos de linguagem experimentados em suportes multimídias, embora ainda não se saiba com precisão como se comportarão os elementos visuais, a organização e formas de acesso ao seu conteúdo.

Ainda não há um modelo estabelecido para interface de TV interativa, tudo depende dos serviços oferecidos pela emissora e das possibilidades de acesso pelo telespectador/usuário. É natural que sua estrutura seja uma adaptação da estrutura utilizada em hipermídias de CD-ROM e de Web. (GOSCIOLA, 2004, p.95).

\section{BREVE HISTÓRICO DA TV DIGITAL NO BRASIL}

A televisão se consolidou como principal meio de comunicação de massa no decorrer de sua evolução desde seu surgimento em meados do século XX. Paralelamente a isso, e com grande vigor a partir dos anos 1990 até a atualidade, os computadores vêm se sofisticando cada vez mais, consolidando-se, por sua vez, como ferramenta de interação informacional pelas possibilidades de conexão em rede.

A principal característica da televisão, enquanto meio de comunicação, diz respeito ao tipo de difusão do conteúdo. Normalmente, um produto televisivo é criado para atender a um público-alvo bastante diverso. Embora a segmentação já seja possível em sistemas mais avançados de transmissão, em sua história essa possibilidade foi sempre muito restrita.

O computador em rede, por sua vez, permite uma personalização cada vez mais eficiente do conteúdo pelos seus provedores. Os sistemas computacionais e a comunicação pela Internet podem enviar um conteúdo absolutamente individualizado, conforme hábitos 


\section{ARTIGO \\ Comunicação \& Tecnologia}

de navegação registrados pelas estatísticas de acesso, cuja identificação é possível pelos protocolos de comunicação da rede mundial de computadores $\left(\mathrm{IP}^{2}\right)$.

Atualmente no Brasil, se vislumbra uma possibilidade bastante concreta de convergência tecnológica desses dois aparatos, assim como o desenvolvimento de um equipamento que integra sistemas digitalizados de produção e envio dos conteúdos e permite uma interação entre emissor e receptor, numa interface já consagrada e muito difundida: a Televisão Digital Interativa.

$\mathrm{Na}$ verdade, trata-se da televisão como a conhecemos com os processos de produção, encapsulamento, envio e recepção de sinais totalmente digitalizados. Dependendo do sistema adotado, poderão ser incorporadas algumas possibilidades de interação do usuário com o sistema, com o conteúdo ou com seus provedores. Assim, como com o surgimento da Internet, a implementação da TV Digital Interativa deve transformar o meio de comunicação original que lhe serviu como suporte, se configurando num novo ambiente de comunicação que soma características e possibilidades de vários meios e aparatos pré-existentes.

Prevendo esses avanços e todas as transformações decorrentes, Estado, organizações civis e de pesquisa se articulam para a criação de normas, padrões e políticas de implementação do novo sistema.

Em 2003, o presidente da república baixou, via Ministério das Comunicações, o decreto que instituiu o Sistema Brasileiro de Televisão Digital SBTVD. A instituição tem, entre seus fins, o objetivo de planejar e viabilizar o processo de transição da televisão analógica para o sistema digital (BRASIL, 2003). Além disso, ficou documentada no decreto a intenção de promover a inclusão digital, além de "propiciar a criação de rede universal de educação à distância” (Art. $1^{\circ}$, inciso nº II).

A decisão quanto ao sistema tecnológico escolhido, que servirá de padrão para a indústria, caberá ao Governo Federal, que deve avaliar as considerações elaboradas pelas comissões e órgãos envolvidos.

${ }^{2}$ Internet Protocol

(C) ETD - Educação Temática Digital, Campinas, SP, v.5, n.2, p.7-22, jun. 2004 - ISSN: 1517-2539. 12 


\section{ARTIGO \\ Comunicação \& Tecnologia}

Grosso modo, três sistemas disputam o aval oficial para serem implementados como padrão nacional: o primeiro, baseado no sistema norte-americano; um segundo, baseado no sistema europeu; e o terceiro, que tem base no sistema japonês. Há ainda uma proposta brasileira, que pretende incorporar características e qualidades dos 3 sistemas anteriores.

O Centro de Pesquisa e Desenvolvimento em Telecomunicações (CPqD) está desenvolvendo essa proposta híbrida de padrão de sistema, junto com a Faculdade de Educação (FE) da Unicamp - Universidade Estadual de Campinas. As pesquisas dessas instituições pretendem desenvolver tecnologias e serviços para a nova plataforma de comunicação.

A proposta almeja uma aplicação em "temas tais como telemedicina, entretenimento, mensagem, comunicação, transação e informação" (AMARAL; PACATA, 2003) além, claro, do enfoque educacional pesquisado pela FE. Abrange, portanto, o uso comercial aberto da transmissão dos conteúdos a partir da implementação nacional conforme o padrão escolhido.

Os serviços oferecidos nos protótipos do CPqD fazem parte do Projeto TV Digital Interativa, financiado com recursos do Funttel (Fundo para Desenvolvimento Tecnológico das Telecomunicações).

Os experimentos serão executados em 3 escolas do Ensino Fundamental de Barão Geraldo, distrito de Campinas (SP), a partir de 2004/2005.

O padrão escolhido pelo Governo deverá integrar transmissão via satélite, telefonia fixa e Internet em banda larga para tornar disponível aos usuários textos, imagens e som. Diferentemente do sistema original analógico, a TV Digital, se interativa, possibilitará a transmissão de conteúdos complementares, guias didáticos e de orientação, tabelas, artigos, além de conteúdos que poderão ser enviados de volta ao provedor do serviço ou da programação. A recepção via satélite e o retorno possibilitado pelas redes de telefonia fixa têm alcance em praticamente todo o território brasileiro.

(c) ETD - Educação Temática Digital, Campinas, SP, v.5, n.2, p.7-22, jun. 2004 - ISSN: 1517-2539. 


\section{ARTIGO \\ Comunicação \& Tecnologia}

\section{A TV DIGITAL INTERATIVA COMO NOVO AMBIENTE PARA O GÊNERO DOCUMENTÁRIO}

A TV Digital Interativa é uma realidade próxima neste país. A escolha do modelo técnico definirá a produção dos conteúdos, que muito possivelmente contemplarão alguns atrativos até então nunca vistos naquele que é o mais popular e difundido aparato/meio de comunicação.

O vídeo-documentário como o conhecemos deve acompanhar a revolução prevista com a implementação do novo sistema de tv e acabará incorporando elementos de conteúdo antes desconsiderados em sua produção, originalmente fílmica.

Este estudo inicia uma discussão sobre a apropriação dos elementos de linguagem que possivelmente comporão o documentário na TV Digital Interativa, sugerindo uma evolução da modalidade de documentário que, preliminarmente, será chamada Documentário Interativo Digital.

Essa nomenclatura é aqui adotada por contemplar os conceitos utilizados na tecnologia da nova tv (Interatividade e Digital), além de obviamente preservar o termo principal, documentário, definido no início deste texto.

O adjetivo digital é considerado em relação ao significado atual do termo, associado apenas com o suporte técnico envolvido, não cabendo, aqui, aprofundamentos desnecessários. É entendido, portanto, como um sistema que trata de sinais digitais ou digitalizados e que representa dados ou quantidades físicas na forma numérica (usando um sistema binário em dispositivos relacionados com computadores) (UOL, 2002).

O termo interatividade tem sido utilizado com vários níveis de significação, principalmente após a proliferação das novas tecnologias nos meios de comunicação. $\mathrm{Na}$ televisão, a possibilidade de votação por telefone para a escolha de um filme em determinado horário, uma forma de intervenção do público na programação das emissoras, é um exemplo de uso da palavra num aspecto bastante específico e limitado do termo. 


\section{ARTIGO \\ Comunicação \& Tecnologia}

Derivado do conceito de interação, substantivo que define a ação recíproca entre dois corpos, uns nos outros (UOL, 2002), a expressão interatividade passou a se relacionar cada vez mais com os meios e sistemas computacionais surgidos com o avanço das novas tecnologias, nos anos 1960. De lá para cá, a partir da evolução dos dispositivos de entrada e saída de dados e gerenciamento das informações em plataformas que suportam o uso simultâneo por vários usuários, interatividade passou a ser entendida como a relação “de quanto um usuário pode participar ou influenciar na modificação imediata, na forma e no conteúdo de um ambiente computacional (...) baseada no tempo de resposta ao estímulo.” (BECKER ; MONTEZ, 2004, p.47).

É nesse sentido, essencialmente relacionado com o uso de equipamentos e sistemas computacionais, que o termo será considerado neste trabalho.

Além de considerar a interação entre indivíduos mediados pelos sistemas computacionais, é importante salientar a interação possível com o próprio sistema ou conteúdo veiculado em ambientes interativos, como será o caso das primeiras versões do documentário na tv digital. Nesse caso, a interação permite uma navegação não-linear ou mesmo multi-linear, onde a escolha quanto o acesso e profundidade pretendidos é opção exclusiva do usuário, movido por sua curiosidade ou interesse, como será visto a seguir.

\section{O DOCUMENTÁRIO E A APROPRIAÇÃO DE ELEMENTOS DE LINGUAGEM DA TV DIGITAL INTERATIVA}

A proposta de um Documentário Interativo Digital, veiculado num suporte televisivo, sugere um “eixo central” de narração com as características do documentário convencional, pela maneira consagrada como a televisão é utilizada e seus conteúdos são fruídos. Ou seja, o filme documentário continuará transmitindo sua mensagem numa lógica predominantemente linear, pela qual o telespectador simplesmente observa o conteúdo ao se dispor diante da tv. Isso significa que ainda haverá, na TV Digital Interativa, a possibilidade da recepção passiva do documentário, qualidade principal do produto fílmico herdada do cinema. 


\section{ARTIGO \\ Comunicação \& Tecnologia}

Ainda assim, e pelas potencialidades esperadas da tv digital, as características principais a serem exploradas pela equipe produtora do documentário são consideradas em um grupo denominado TV Avançada (Enhanced TV), entendido como

(...) conteúdo televisivo que engloba texto, vídeo e elementos gráficos, como fotos e animações. Na sua forma mais simples, é a apresentação integrada desses elementos (...). A principal diferença para a TV analógica consiste justamente na integração desses elementos e no aumento da qualidade do vídeo e do som. (BECKER ; MONTEZ, 2004, p.54).

O principal aspecto da produção documental para o novo suporte diz respeito à possibilidade de interação entre o telespectador, chamado doravante de usuário, e o filme. A interatividade, conforme descrita anteriormente, possibilitará uma nova experiência de fruição diante do Documentário Interativo Digital.

Num primeiro momento, a interatividade no documentário se dará com o sistema e o próprio produto por meio da manipulação não-linear do conteúdo.

O que diferencia o ato de ler-ver-ouvir-usar uma hipermídia, ou um hipertexto, do ato de ler um livro é a possibilidade de acesso direto e preciso (até mesmo randômico) a uma informação em particular entre as muitas informações que compõem um conjunto de conteúdos. (GOSCIOLA, 2003, p.99)

Um exemplo dessa natureza de recurso são os conteúdos complementares existentes em DVDs encontrados no mercado. Normalmente, é possível assistir entrevistas com diretores, atores e/ou produtores do filme contido naquela mídia; ou ainda, consultar fichas técnicas, making off, dados e textos complementares, etc. Tais consultas podem ser feitas durante a exibição do filme ou a partir de uma interrupção momentânea do conteúdo fílmico.

Entretanto, com o Documentário Interativo Digital espera-se mais que informações de produção e bastidores, como acontece nos produtos como o descrito acima. Espera-se que os conteúdos complementares sejam relativos ao assunto do documentário produzido, que as informações sobre o tema abordado estejam disponíveis por meio de recursos 


\section{ARTIGO \\ Comunicação \& Tecnologia}

multimídia e incorporados à exibição do filme documentário conforme as possibilidades técnicas próprias da TV Digital Interativa.

Essa expectativa agrega ao conceito da não-linearidade de GOSCIOLA (2003, p.99) uma possibilidade de multi-linearidade, já que os vários conteúdos disponíveis de forma linear (paralelos ou transversais) poderão ser acionados arbitrariamente pelo usuário, e as interrupções permitirão um desvio por outro caminho sugerindo um parêntese àquele trajeto linear original, sempre com a capacidade de retorno ao percurso anteriormente seguido. Assim, "a possibilidade de escolher o caminho narrativo passa a ser da responsabilidade do leitor [telespectador], que antes era o autor.” (GOSCIOLA, 2003, p.101).

Essa navegação definida pelo usuário que, seguindo pelo "eixo central” do documentário fílmico depara-se com a possibilidade de desvios interativos, causa diferentes construções de sentidos para o indivíduo, gerando, portanto, vários discursos conforme o percurso seguido.

Liestol (1997, p.119) apresenta o conceito de discurso decorrido para o estudo da linguagem hipertextual numa experiência não-linear de exploração do conteúdo. Para o autor, o discurso armazenado é aquele que contém toda a obra definida pelo conteúdo; discurso decorrido é aquele construído conforme o percurso realizado pelo usuário na exploração do conteúdo armazenado, por meio dos recursos do hipertexto.

Na Web, o documentário exige uma postura essencialmente pró-ativa do usuário diante do conteúdo, determinando sempre a construção de um discurso decorrido. No cinema, com o documentário convencional, a postura do telespectador é passiva, mesmo quando a narrativa é apresentada a partir da exploração de formas de fragmentação do roteiro, no espaço e tempo, desvendando, sempre, o discurso armazenado.

Possivelmente, na TV Digital Interativa, o documentário exigirá do usuário uma postura híbrida em relação à exploração do conteúdo: haverá momentos de fruição passiva, similares ao comportamento diante do documentário convencional, e outros em que o tráfego por conteúdos paralelos ou transversais será possível somente quando acionados pelo usuário, despertando, portanto, uma postura fundamentalmente pró-ativa. 


\section{ARTIGO Comunicação \& Tecnologia}

Um exemplo de trajeto paralelo pode ser a exibição de conteúdos inter-relacionados na mesma interface: o conteúdo fílmico principal do documentário é veiculado numa área reduzida enquanto outros elementos, multimídias, textuais ou gráficos, podem ser explorados simultaneamente pelo usuário numa área distinta ou sobrepostos às imagens. Essa capacidade deve ser potencializada com a tv digital, que utiliza uma tela retangular, de proporção ${ }^{3}$ 16:9 (a analógica tem formato 4:3), cerca de 10\% a mais de área útil para a direita e $10 \%$ a mais de área útil para a esquerda, espaço a ser explorado pelos desenvolvedores da interface (GOSCIOLA, 2003, p.95).

Já o trajeto transversal obedece à lógica fundamental do hipertexto e permite uma variedade de caminhos possíveis que, em tese, não comprometem a exploração do "eixo central” do documentário, como aqui proposto. Pelo controle remoto, a qualquer instante o usuário poderá acionar conteúdos extras àquele veiculado em cada momento (cena), ou ainda consultar informações relacionadas ao tema do filme assistido. Quando considerar que aquele conteúdo complementar fora superado ou alcançar a profundidade desejada em relação ao assunto, o usuário retomará o "eixo central” do documentário no ponto onde houvera interrompido a exibição do filme.

Mesmo que o documentário seja transmitido pela primeira vez pela emissora ou provedor de conteúdo digital para a TV Digital Interativa, a interrupção será possível sem a perda da continuidade do programa, pois a tv digital incorpora em si um sistema denominado Personal Vídeo Recorder (PVR) ${ }^{4}$.

Essa função pode suspender a reprodução do programa, mesmo que ele esteja acontecendo ao vivo, e retomar sua reprodução do ponto em que foi parado (...). Vem com disco rígido, onde fica armazenado o vídeo, que eventualmente pode ser redistribuído posteriormente. (BECKER, MONTEZ, 2004, p.55).

O usuário poderá, ainda, fazer o download do produto documentário a ser exibido e ter todo seu conteúdo armazenado no disco rígido, para ser assistido e explorado a qualquer momento conforme sua necessidade ou conveniência (sob demanda).

\footnotetext{
${ }^{3}$ A proporção define largura:altura.

${ }^{4}$ Também conhecido como Personal TV ou Digital Video Recorder (DVR).
} 


\section{ARTIGO \\ Comunicação \& Tecnologia}

Essas possibilidades e formas de uso/fruição do documentário na TV Digital Interativa vão requerer da equipe produtora dos conteúdos uma roteirização específica, voltada aos ambientes multi e hipermídias, conforme atribui Gosciola:

Cabe à roteirização definir a ordem dos conteúdos. (...) determinar os comportamentos dos links. (...) visar obstinadamente o processo comunicacional. (...) se dispor a prever aquilo que acontecerá entre o usuário e a obra. (...) atentar para o que o usuário receberá e apreenderá da obra, diferentemente das preocupações das outras ações da realização de uma hipermídia. E, assim, cabe à roteirização garantir, juntamente com as outras ações, uma plena utilização da hipermídia. (2004, p.235-236).

É evidente que a ordenação e execução das muitas atividades envolvem muitas áreas e “diversos campos de trabalho - vídeo, áudio, gráfico, texto, interatividade, diagramação, etc. - desenvolvidos simultaneamente” (GOSCIOLA, 2004, p.236). Normalmente, a produção documentarista e a formulação de um roteiro para o conteúdo são atividades do profissional comunicólogo, geralmente jornalista, que deve deter conhecimentos mínimos dessas áreas e das possibilidades técnicas envolvidas com o meio hipermídia e, principalmente, com a TV Digital Interativa.

Por fim, para fechar esta discussão preliminar sobre a utilização do gênero documentário na tv digital, é necessário definir seu papel enquanto produto gerador de conhecimento e de vocação educacional implícita.

A interatividade no ambiente da tv digital, como descrito anteriormente, prevê ferramentas de interação do usuário com o provedor do serviço e a possibilidade de sua influência na modificação da forma e do conteúdo originalmente distribuído, gerando um sentido pleno no terreno educativo (AMARAL; PACATA, 2003).

Becker e Montez propõem um nível de interatividade na tv digital para que:

O telespectador possa ter uma presença mais efetiva no conteúdo, saindo da restrição de apenas escolher as opções defendidas pelo transmissor. (...) Para isso, torna-se necessário um canal de retorno ligando o telespectador à emissora, chamado de canal de interação. (2004, p.53).

Essa possibilidade permitirá ao usuário interagir e intervir na produção dos conteúdos. Para os processos de ensino-aprendizagem, o uso do documentário ou outras produções específicas para a TV Digital Interativa pode significar um avanço sem 


\section{ARTIGO \\ Comunicação \& Tecnologia}

precedentes, pois deve compor, num mesmo meio, recurso e sistemas de informação que exploram determinados assuntos assim como os respectivos processos de avaliação relacionados ao tema desenvolvido. Nesse sentido, a ferramenta possibilitará o fluxo completo das atividades educativas suportadas num meio específico e com o apelo das transmissões televisivas, permitindo "serviços para a teleducação que têm como eixo uma pedagogia comunicacional de apoio ao professor em sala de aula, apoio ao estudante em casa e interação pais-escola” (AMARAL; PACATA, 2003).

\section{CONSIDERAÇÕES FINAIS}

Três aspectos fundamentais dão base às reflexões apresentadas neste artigo. Primeiro, aquele que argumenta sobre a relação da evolução da linguagem documental conforme o meio onde é veiculado o produto, e para o qual ele é produzido. No cinema, meio onde o gênero surgiu, os recursos de linguagem são aqueles próprios da narrativa fílmica. A gênese comum consagrou o documentário enquanto produto fílmico: todos sabemos que um documentário é, antes de qualquer coisa, um filme.

Mesmo assim, o avanço das tecnologias computacionais permitiu que o gênero migrasse a outros ambientes e admitisse novos usos. Na Web, o documentarismo passou a explorar outras linguagens e a utilizar novos recursos, impossíveis no suporte convencional analógico. Atualmente, a TV Digital Interativa se apresenta como novo suporte e meio de veiculação do gênero documentário, que agrega possibilidades técnicas e de linguagem comuns às da Web e cinema, juntos.

O segundo aspecto propõe preliminarmente quais seriam essas capacidades e como os recursos da tv digital poderiam ser explorados pelo documentário. Essa união de possibilidades de uso, principalmente a capacidade interativa, dá indícios de como serão as novas produções, que deverão prever conteúdos antes descartados na produção fílmica assim como a elaboração de roteiros específicos, voltados às multimídias. As novas produções também deverão requerer profissionais com conhecimentos técnicos específicos, 


\section{ARTIGO \\ Comunicação \& Tecnologia}

relacionados aos diferentes suportes envolvidos na produção e veiculação do produto, em especial a TV Digital Interativa.

Por fim, o terceiro aspecto sugere a aplicação do Documentário Interativo Digital nos processos de ensino-aprendizagem, pela apropriação dos elementos de linguagem e possibilidades técnicas da TV Digital Interativa, e sua capacidade para a produção e transmissão do conhecimento.

Tais abordagens não pretenderam ser definitivas. Ao contrário disso, apresentaram alguns elementos iniciais para a reflexão dos estudiosos e profissionais envolvidos com o assunto. O gênero, consagrado no meio fílmico, deve acompanhar a evolução das novas tecnologias. Seus produtores, por conseguinte, devem conhecer os aspectos e características da nova mídia, necessários para assumir e explorar seus recursos.

\section{REFERÊNCIAS}

AMARAL, Sérgio Ferreira do, PACATA, Daniel Moutinho. A TV Digital Interativa no espaço educacional. Jornal da Unicamp, Campinas, n. (edição) 229, 15 a 21 set. 2003. Disponível em:<http://www.unicamp.br/unicamp/unicamp_hoje/jul/setembro2003/ju229 pg2b.html>. Acesso em: 11 mar. 2004.

BECKER, Valdecir; MONTEZ, Carlos. TV digital interativa: conceitos, desafios e perspectivas para o Brasil. Florianópolis: 12TV, 2004.

BRASIL. Ministério das Comunicações. Atos do poder executivo. Telecomunicações: TV Digital. Decreto no 4901, 26 nov. 2003. Edição Número 231, 27 nov. 2003.

GOSCIOLA, Vicente. Roteiro para as novas mídias: do game à tv interativa. São Paulo: Editora Senac, 2003.

GREGOLIN, Maira, SACRINI, Marcelo, TOMBA, Rodrigo Augusto. Webdocumentário: uma ferramenta pedagógica para o mundo contemporâneo. Campinas, 2002, 120f. (Trabalho de Conclusão de Curso) - Faculdade de Jornalismo, Pontifícia Universidade Católica de Campinas, Campinas, 2002.

GRIERSON, John. First principles of documentary. London: Faber \& Faber, 1979.

(c) ETD - Educação Temática Digital, Campinas, SP, v.5, n.2, p.7-22, jun. 2004 - ISSN: 1517-2539. 


\section{ARTIGO \\ Comunicação \& Tecnologia}

LIESTOL, Gunnar. Wittgenstein, Genette y la narrativa del lector em hipertexto. In: LANDOW, George P. (Org.). Teoria del hipertexto. Barcelona: Paidós, 1997.

PENÁFRIA, Manuela. (1999) Perspectivas de desenvolvimento para o documentarismo. Disponível em: <http://www.bocc.ubi.pt/pag/_texto.php3?html2= penafria-perspectivasdocumentarismo.html>. Acesso em: 15 ago. 2002.

UOL Dicionário Michaelis. São Paulo: FSP, 2002. (Publicado em CD ROM)

WINSTON, Brian. Claming the real: the documentary film revisited. London: BFI British Film Institute Publishing, 1995.

MARCELO SACRIN

Redator Web da Pontifícia Universidade Católica de Campinas, Jornalista,

Especialista em Informática em Educação

pela Universidade Federal de Lavras

Professor de Jornalismo On-line

e-mail: Hsacrini@puc-campinas.edu.brH / Hsacrini@gmail.comH

(19) 3756-7353 - (11) 9936-2332

Recebido em: 25/06/2004

Aceito em: 26/07/2004 